\title{
Erratum
}

\section{Pattern Recognition and Associative Memory as Dynamical Processes in a Synergetic System}

\author{
A. Fuchs and H. Haken
}

Biol. Cybern. 60, 17-22 (1988)

In (5) of our paper [1], in the decomposition of $q^{+}$, the variable $q_{k}$ must be replaced by $q^{k}$ so that

$\mathbf{q}^{+}=\sum_{k=1}^{M} q^{k} \mathbf{v}^{(k)}+\mathbf{w}$

This substitution must also be made everywhere in (6):

$$
\begin{aligned}
V\left(q^{k}\right)= & -\frac{1}{2} \sum_{k=1}^{M} \lambda_{k}\left(q^{k}\right)^{2}+\frac{1}{4} B \sum_{k \neq k^{\prime}}^{M}\left(q^{k}\right)^{2}\left(q^{k^{\prime}}\right)^{2} \\
& +\frac{1}{4} C\left\{\sum_{k=1}^{M}\left(q^{k}\right)^{2}+|\mathbf{w}|^{2}\right\}^{2}
\end{aligned}
$$

Equation (8) becomes superfluous, while (7) and (9) simplify to

$\dot{q}^{j}=-\frac{\partial V}{\partial q^{j}}, \quad \dot{\mathbf{w}}=-\frac{\partial \mathbf{V}}{\partial \mathbf{w}}$,

$$
\begin{aligned}
\dot{q}^{j}= & \lambda_{j} q^{j}-B \sum_{k \neq j}^{M}\left(q^{k}\right)^{2} q^{j} \\
& -C\left\{\sum_{k=1}^{M}\left(q^{k}\right)^{2}+|\mathbf{w}|^{2}\right\} q^{j}, \\
\dot{\mathbf{w}}= & -C\left\{\sum_{k=1}^{M}\left(q^{k}\right)^{2}+|\mathbf{w}|^{2}\right\} \mathbf{w} .
\end{aligned}
$$

Equations $\left(9^{\prime}\right)$ are straightforward generalizations of (4.37) in [2] to $\mathbf{w} \neq \mathbf{0}$. Incidentally, in this way we avoid an (erroneous) omission of terms in (9). We wish to thank P. Schiske for drawing our attention to these omissions. The further results of our paper remain unchanged, however.

\section{References}

1. Fuchs A, Haken $H($ (1988) Pattern recognition and associative memory as dynamical processes in a synergetic system. Biol Cybern 60:17-22

2. Haken H (1987) In: Haken H (ed) Computational systems, natural and artificial. Springer, Berlin Heidelberg New York 